\title{
PENGARUH MODEL PEMBELAJARAN KOOPERATIF TIPE TEAM ACCELERATED INSTRUCTION (TAI) TERHADAP KEMAMPUAN PEMECAHAN MASALAH DALAM PEMBELAJARAN MATEMATIKA MATERI POLA BILANGAN
}

\author{
Aniyatul Jaziroh ${ }^{1}$ \\ ${ }^{1}$ SDIT Ambarawa, Indonesia. \\ aniyatuljaziroh@gmail.com
}

\begin{abstract}
Abstrak
Penelitian ini bertujuan untuk mengetahui pengaruh model pembelajaran kooperatif tipe Team Accelerated Instruction (TAI) terhadap kemampuan pemecahan masalah dalam pembelajaran matematika, dan untuk mengetahui seberapa besar pengaruh model pembelajaran kooperatif tipe Team Accelerated Instruction (TAI) terhadap kemampuan pemecahan masalah dalam pembelajaran matematika. Jenis penelitian ini adalah penelitian kuantitatif quasi eksperimental dengan desain pretest - posttest control group design. Pengambilan sampel dalam penelitian ini dilakukan secara purposive sampling yaitu kelas VIII A (kelas eksperimen) dan VIII B (kelas kontrol). Teknik pengumpulan data menggunakan soal dan dokumentasi. Pengujian hipotesis dilakukan uji regresi linear sederhana, dan koefisien determinasi. Hasil penelitian menunjukkan bahwa penggunaan model pembelajaran kooperatif tipe Team Accelerated Instruction (TAI) berpengaruh terhadap kemampuan pemecahan masalah matematika materi pola bilangan. Hal tersebut dapat dilihat dari rata-rata posttest kelas eksperimen 69,10 dan rata-rata kelas kontrol 53,21. Dari pengujian regresi linear sederhana nilai (Sig.) sebesar 0,000 lebih kecil dari probabilitas 0,05, sehingga dapat disimpulkan bahwa $\mathrm{H}_{0}$ diterima sehingga terdapat pengaruh model pembelajaran kooperatif tipe Team Accelerated Instruction (TAI) terhadap kemampuan pemecahan masalah dalam pembelajaran matematika. Kemudian didapat nilai koefisien determinasi $R$ Square adalah 0,415 , jadi besarnya pengaruh model pembelajaran kooperatif tipe Team Accelerated Instruction (TAI) terhadap kemampuan pemecahan masalah sebesar 41,5\%.
\end{abstract}

Kata Kunci: Team Accelerated Instruction (TAI), Kemampuan Pemecahan Masalah Matematika, Pola Bilangan.

\begin{abstract}
This study aims to determine the effect of the Team Accelerated Instruction (TAI) cooperative learning model on problem solving abilities in mathematics learning, and to find out how much influence the Team Accelerated Instruction (TAI) cooperative learning model has on the ability to solve problems in mathematics learning. This type of research is a quantitative quasi experimental study with a pretest posttest control group design. Sampling in this study was conducted by purposive sampling, namely class VIII A (experimental class) and VIII B (control class). Data collection techniques using question and documentation. Hypothesis testing is done by a simple linear regression test, and the coefficient of determination. The results showed that the use of the Team Accelerated Instruction (TAI) cooperative learning model affected the mathematical problem solving ability of number pattern material. This can be seen from the average posttest of the experimental class 69.10 and the average control class of 53.21. From the simple linear regression test the value (Sig.) Of 0,000 is smaller than the probability of 0.05, so it can be concluded that $H_{0}$ is accepted so that there is an influence of the Cooperative Learning model type Team Accelerated Instruction (TAI) on problem solving skills in mathematics learning. Then the $R$ Square determination coefficient value is 0.415 , so the magnitude of the influence of the Team Accelerated Instruction (TAI) type of cooperative learning model on problem solving skills is $41.5 \%$.
\end{abstract}

Keywords: Team Accelerated Instruction (TAI), Problem Solving Ability Mathematics, Number Patterns. 


\section{Jurnal Hipotenusa, 1 (1), Desember 2019}

Aniyatul Jaziroh

\section{PENDAHULUAN}

Matematika merupakan ilmu yang sangat penting untuk dipelajari, matematika merupakan salah satu mata pelajaran yang menduduki peranan penting dalam pendidikan dan merupakan salah satu mata pelajaran yang diujikan dalam Ujian Nasional mulai dari tingkat SD sampai dengan SMA. Pembelajaran matematika bertujuan agar siswa dapat memahami konsep matematika yang bersifat abstrak dan mampu menerapkan dalam kehidupan sehari-hari. Tugas utama guru adalah menyampaikan konsep kepada siswa dan harapannya siswa dapat memahami dan menerima konsep itu dengan mudah. Namun pada kenyataannya yang terjadi dilapangan siswa hanya menghafal konsep dan kurang mampu untuk menggunakan konsep tersebut jika menemui masalah dalam kehidupan nyata yang berhubungan dengan konsep yang dimiliki (Trianto, 2011: 65).

Dalam pendidikan matematika, pemecahan masalah adalah hal yang penting untuk ditanamkan pada diri siswa. Karena suatu konsep atau prinsip akan bermakna jika diaplikasikan dalam pemecahan masalah. Menurut Mulyasa, (2008: 111) yang menyatakan bahwa pemecahan masalah memegang peranan penting terutama agar pembelajaran dapat berjalan dengan fleksibel.

Matematika secara abstrak langsung disampaikan oleh guru kepada siswa, sehingga cara seperti ini hanya menanamkan konsep sementara dan gampang dilupakan. Untuk memberikan pemahaman konsep materi yang diajarkan agar dapat digunakan dan dingat juga bagi siswa. Guru dapat membuka wawasan siswa dengan model pembelajaran yang berbasis permainan, agar siswa tidak hanya tahu mengenai konsep tetapi dapat memahami, mengingat dan menggunakan konsep tersebut.

Madrasah Tsanawiyah (MTs) NU Salatiga adalah salah satu MTs di Kota Salatiga yang merupakan lembaga pendidikan yang bertanggung jawab untuk mempersiapkan para generasi muda demi kemajuan bangsa dan Negara Indonesia. Berdasarkan pengamatan peneliti di MTs NU Salatiga masih banyak siswa yang hanya memahami konsep tetapi belum bisa mengaplikasikan pada sebuah pemecahan masalah. Terutama pada pembelajaran matematika banyak siswa yang menghindarinya, karena dianggap sulit, membosankan, dan hanya berisi tentang rumus. Sehingga dampaknya adalah banyak siswa yang tidak paham, malas dalam pembelajaran matematika. Hal tersebut terlihat saat pembelajaran matematika siswa sering ijin kekamar mandi, tidur, mengobrol dengan temannya, dll. Untuk itu proses belajar mengajar juga kurang maksimal sehingga berdampak pada kemampuan pemecahan masalah siswa MTs NU Salatiga, masih banyak nilai siswa yang dibawah KBM. Dari hasil nilai ulangan harian siswa kelas VIII A yang berjumlah 28 siswa hanya 2 siswa yang nilainya mencapai KBM dengan nilai 77,5 dan 75 dengan nilai KBM 74 pada mata pelajaran matematika.

Dalam dunia pendidikan, kegiatan belajar mengajar adalah kegiatan yang paling inti. Berhasil tidaknya tujuan pendidikan tergantung bagaimana kegiatan proses belajar mengajar yang diajarkan kepada siswa. Oleh karena itu diperlukan adanya model pembelajaran yang dapat meningkatkan kemampuan pemecahan masalah siswa sehingga siswa tidak hanya mengetahui konsep tetapi juga mampu mengaplikasikan dalam bentuk pemecahan masalah.

Salah satu model pembelajaran yang dapat digunakan adalah model pembelajaran kooperatif tipe Team Accelerated Instruction (TAI). Dengan model pembelajaran ini diharapkan mampu memperbaiki kemampuan pemecahan masalah siswa sehingga nilai siswa dapat mencapai KBM yang ditetapkan. Model pembelajaran kooperatif tipe Team Accelerated Instruction (TAI) merupakan model pembelajaran yang mengkombinasikan antara pembelajaran kooperatif dan pembelajaran individual. Selain itu dengan adanya model pembelajaran ini dapat meningkatkan motivasi belajar siswa, melatih siswa untuk bekerja secara kelompok, dan juga dapat mengurangi anggapan bahwa pembelajaran matematika itu sulit.

Berdasarkan latar belakang yang telah dipaparkan di atas maka dilakukan penelitian dengan judul "Pengaruh Model Pembelajaran Kooperatif Tipe Team Accelerated Instruction (TAI) Terhadap Kemampuan Pemecahan Masalah Dalam Pembelajaran Matematika Materi Pola Bilangan"

\section{METODE}

Penelitian ini merupakan penelitian kuantitatif dengan pendekatan atau strategi yang 


\section{Jurnal Hipotenusa, 1 (1), Desember 2019}

Aniyatul Jaziroh

digunakan adalah quasi experimental design (eksperimen semu). Dengan menggunakan pretest-posttest only control group design yakni menempatkan subyek penelitian ke dalam dua kelas yang dibedakan menjadi kategori kelas eksperimen dan kelas kontrol serta kedua kelas tersebut dipilih secara purposive sampling (Sugiyono, 2017: 114).

Kelas eksperimen diberi perlakuan dengan menggunakan model Team Accelerated Instruction (TAI), sedangkan kelas kontrol dengan pembelajaran yang biasnya digunakan oleh guru yaitu pembelajaran konvensional. Adapun desain pretest-postest control group design adalah sebagai berikut:

Gambar 1. Desain Penelitian

\begin{tabular}{|llll|}
\hline $\mathrm{E}$ & $\mathrm{O}_{1}$ & $\mathrm{X}$ & $\mathrm{O}_{2}$ \\
$\mathrm{~K}$ & $\mathrm{O}_{3}$ & & $\mathrm{O}_{4}$ \\
\hline
\end{tabular}

Keterangan:

E : Keadaan awal kelompok eksperimen

$\mathrm{K}$ : Keadaan awal kelompok kontrol

$\mathrm{X} \quad$ : Treatment (perlakuan)

$\mathrm{O}_{1} \quad$ : Hasil penilaian pretest terhadap kelompok eksperimen

$\mathrm{O}_{2} \quad$ : Hasil penilaian pretest terhadap kelompok kontrol

$\mathrm{O}_{3} \quad$ : Hasil penilaian posttest terhadap kelompok elsperimen

$\mathrm{O}_{4} \quad$ : Hasil penilaian posttest terhadap kelompok kontrol

Desain ini terdapat dua kelompok masingmasing dipilih purposive sampling. Kelompok pertama diberi treatment atau perlakuan (X) dan kelompok yang kedua tidak. Kelompok yang diberi perlakuan disebut kelas eksperimen dan kelompok yang tidak diberi perlakuan disebut kelas kontrol. Kelompok pertama diberi perlakuan model pembelajaran kooperatif tipe Team Accelerated Instruction (TAI) dan kelompok kedua diberi perlakuan metode pembelajaran konvensional. (Purwanto dan Sulistyastuti, 2017: 89)

Dalam penelitian ini yang digunakan sebagai populasi adalah siswa kelas VIII di MTs NU Salatiga tahun ajaran 2019/2020 yang berjumlah 88 siswa yang terbagi menjadi 3 kelas VIII A, VIII B, dan VIII C.

Sedangkan sampel yang digunakan dalam penelitian ini berdasarkan pertimbangan ibu Aprilia Nugrahani, S.Pd sebagai guru pengampu mata pelajaran matematika kelas VIII, peneliti menggunakan kelas VIII A sebagai kelas eksperimen dan VIII B sebagai kelas kontrol dengan alasan kedua kelas tersebut memiliki rata-rata kemampuan yang relatif sama.

Teknik analisis data dalam penelitian ini menggunakan analisis regresi linear untuk mengetahui adanya pengaruh model pembelajaran Team Accelerated Instruction (TAI) terhadap kemampuan pemecahan masalah dalam pembelajaran matematika dan koefisien determinasi untuk mengetahui seberapa besar pengaruh model pembelajaran Team Accelerated Instruction (TAI) terhadap kemampuan pemecahan masalah dalam pembelajaran matematika dengan terlebih dahulu data sudah berdistribusi normal dan homogen.

\section{HASIL DAN PEMBAHASAN}

Pada penelitian ini, peneliti melakukan riset pada MTs NU Salatiga. Sesuai dengan jenis penelitian, peneliti mengambil 2 dari 3 kelas yang ada yaitu kelas VIII A sebagai kelas eksperimen dan kelas VIII B sebagai kelas kontrol. Sebelum penelitian dimulai terlebih dahulu peneliti mengujikan instrumen soal yang akan digunakan sebagai soal pretest dan posttest. Uji coba instrumen dilakukan pada kelas IX yang pernah mendapatkan materi pola bilangan. Setelah uji coba instrumen kemudian hasil uji coba tersebut diuji validitas dan reliabilitasnya. Jika instrumen tersebut sudah valid dan reliabel tersebut baru dapat diberikan kepada siswa kelas eksperimen dan kontrol. Uji coba soal diikuti oleh 16 siswa, pada uji coba instrumen peneliti memiliki 4 soal, dan dari hasil validitas dan reliabilitas 4 soal tersebut valid dan reliabel.

Tahap selanjutnya pada penelitian ini adalah melakukan proses pembelajaran pada kelas eksperimen dan kelas kontrol. Sebelum masuk dalam proses pembelajaran terlebih dahulu peneliti melakukan pretest untuk mengetahui keadaan awal siswa kelas eksperimen dan kontrol. Peneliti menggunakan model pembelajaran kooperatif tipe Team Accelerated Instruction (TAI) pada kelas eksperimen dan pembelajaran konvensional pada kelas kontrol. Model pembelajaran kooperatif tipe Team Accelerated Instruction (TAI) ini merupakan salah satu model pembelajaran yang memadukan antara pembelajaran individu dan kelompok. 
Proses pembelajaran pada kelas eksperimen dilakukan melalui beberapa tahapan seperti: Teams, Placement Test, Teaching Group, Student Creative, Team Study, WholeClass Units, Facts Test, Team Scores and Team Recognition. Nilai pretest juga digunakan untuk pembentukan kelompok pada kelas eksperimen tahap teams. Setelah melakukan proses pembelajaran pada kelas eksperimen dan kontrol, tahap selanjutnya peneliti memberikan posttest kepada kedua kelas tersebut. Hasil posttest terhadap 28 siswa kelas eksperimen dan kontrol bahwa ada perbedaan signifikan antara hasil kelompok kelas eksperimen dan kelas kontrol.

Rata-rata nilai kelas eksperimen dengan model pembelajaran Team Accelerated Instruction (TAI) lebih besar daripada rata-rata nilai kelas kontrol yang menggunakan pembelajaran konvensional. Penggunaan model ini memberikan pengaruh positif pada siswa dikarenakan model ini dapat menciptakan suasana pembelajaran yang efektif. Hal ini terlihat dari siswa yang saling kerjasama dan adanya komunikasi antar anggota kelompok sehingga membuat adanya tukar informasi sesama anggota.

Selain itu penggunaan model pembelajaran Kooperatif tipe Team Accelerated Instruction (TAI) sesuai dengan yang diungkapkan Slavin, bahwa TAI disusun untuk memecahkan masalah dalam proses pembelajaran, misalnya dalam hal kesulitan belajar secara individu. Dalam hal ini TAI dirancang untuk menyelesaikan masalahmasalah teoritis dan praktis dari sistem pengajaran individual. Hal ini yang membuat model Kooperatif tipe Team Acccelarated Instruction (TAI) lebih menarik keaktifan siswa sehingga hasil yang didapatkannya pun lebih baik daripada pembelajaran yang menggunakan model pembelajaran konvensional.

Sebelum melakukan analisis data peneliti melakukan dekriptif statistik yang gunanya untuk mengetahui nilai minimum, nilai maksimun dan juga rata-rata dari kelas eksperimen dan kontrol.

\section{Tabel 1. Deskriptif Statistik}

\begin{tabular}{lcccc}
\hline Hasil & \multicolumn{2}{c}{ Eksperimen } & \multicolumn{2}{c}{ Kontrol } \\
\cline { 2 - 5 } & Pretest & Posttest & Pretest & Posttest \\
Min. & 25 & 50 & 15 & 40 \\
Max. & 70 & 95 & 52,5 & 75 \\
Mean & 40,625 & 69,107 & 32,321 & 53,214 \\
\hline
\end{tabular}

Berdasarkan Tabel 1 didapatkan nilai minimum 25 dan maxsimum 70 dengan rata-rata 40,625 pada pretest kelas ekperimen sedangkan untuk kelas kontrol didapatkan nilai minimum 15 dan maksimum 52,5 dengan rata-rata 32,321. Untuk nilai posttest nilai minimum 50 dan maksimum 95 pada kelas eksperimen dengan rata-rata 69,107 , sedangkan untuk kelas kontrol nilai minimum 40 dan maksimum 75 dengan rata-rata 53,214.

Berdasarkan uji prasyarat yang telah dilakukan data hasil tes kemampuan pemecahan masalah siswa berdistribusi normal, homogen, dan linear sehingga dapat dilakukan pengujian hipotesis dengan menggunakan regresi linear sederhana dan koefisien determinasi. Adapun hasil dari uji regresi linear sederhana disajikan pada Tabel 2.

Tabel 2. Hasil Uji Regresi Linear Sederhana

\begin{tabular}{lrrrrr}
\hline \multicolumn{1}{c}{ Model } & B & $\begin{array}{c}\text { Std. } \\
\text { Error }\end{array}$ & Beta & T & Sig. \\
\hline $\begin{array}{l}\text { Pretest } \\
\text { Eksperimen }\end{array}$ & 42,444 & 6,482 & & 6,548 &, 000 \\
&, 656 &, 153 & 6,44 & 4,298 &, 000 \\
\hline
\end{tabular}

Berdasarkan Tabel 2. Uji regresi linear sederhana diperoleh nilai (Sig.) sebesar 0,000 lebih besar dari probabilitas 0,05, sehingga dapat disimpulkan bahwa $\mathrm{H}_{0}$ diterima, yang berarti bahwa terdapat pengaruh model pembelajaran kooperatif tipe Team Accelerated Instruction (TAI) terhadap kemampuan pemecahan masalah matematika materi pola bilangan.

Selanjutnya untuk mengetahui berapa besar pengaruh pengaruh model pembelajaran kooperatif tipe Team Accelerated Instruction (TAI) terhadap kemampuan pemecahan masalah maka dilakukakan uji koefisien determinasi.

Nilai Koefisien determinasi $\left(R^{2}\right)$ menunjukkan presentase pengaruh semua variabel independen terhadap variabel dependen baik secara parsial maupun simultan. Koefisien determinasi dapat dirumuskan sebagai berikut (Putro dan Kamal, 2013: 2):

$$
K D=R^{2} \times 100 \%
$$

Keterangan:

$K D \quad$ : Koefisien Determinasi

$R^{2} \quad$ : Koefisien Korelasi yang dikuadratkan 
Tabel 3. Uji Koefisien Determinasi

\begin{tabular}{crrr}
\hline $\mathrm{R}$ & $\mathrm{R}$ Square & $\begin{array}{c}\text { Adjusted R } \\
\text { Square }\end{array}$ & $\begin{array}{l}\text { Std. Error of } \\
\text { the Estimate }\end{array}$ \\
\hline, 644 &, 415 &, 393 & 9,9360 \\
\hline
\end{tabular}

Pada Tabel 3 diketahui bahwa $R$ Square adalah 0,415 kemudian kita masukkan ke rumus:

$$
\begin{aligned}
& K D=R^{2} \times 100 \% \\
& K D=0,415 \times 100 \% \\
& K D=41,5 \%
\end{aligned}
$$

Jadi besarnya pengaruh model pembelajaran kooperatif tipe Team Accelerated Instruction (TAI) terhadap kemampuan pemecahan masalah sebesar $41,5 \%$.

Berdasarkan uraian pembahasan di atas dapat ditarik kesimpulan bahwa model pembelajaran kooperatif tipe Team Accelerated Instruction (TAI) dapat mempengaruhi kemampuan pemecahan masalah siswa. Dan besar pengaruh model pembelajaran kooperatif tipe Team Accelerated Instruction (TAI) terhadap kemampuan pemecahan masalah sebesar $41,5 \%$. Hal ini dapat dilihat dari ratarata kemampuan pemecahan masalah siswa kelas eksperimen lebih tinggi dibandingkan dengan kelas kontrol.

Model pembelajaran kooperatif tipe Team Accelerated Instruction (TAI) ini merupakan perpaduan antara model pembelajaran individu dan kelompok, dalam model ini pembentukan kelompok berdasarkan nilai tinggi, sedang dan rendah. Sehingga kelompok satu dengan kelompok lainnya mempunyai kapasitas yang sama. Dengan adanya perpaduan ini siswa yang kurang paham akhirnya dapat dibantu dengan siswa yang mempunyai kemampuan lebih. Selain itu adanya model ini juga dapat meningkatkan motivasi belajar siswa sehingga siswa tidak jenuh dalam proses belajar mengajar, jadi penggunaan model ini dapat mempengaruhi kemampuan pemecahan masalah siswa.

Hasil penelitian ini relevan dengan penelitian yang dilakukan oleh Hiwaman (2016) yang menyatakan bahwa model TAI ini disusun untuk memecahkan masalah dalam proses pembelajaran. Misalnya dalam hal kesulitan belajar siswa secara individual. Dalam pelaksanaan model ini anggota tim saling memeriksa hasil dari kelompoknya, dan semua anggota tim bertanggung jawab atas jawab dari kelompoknya. Diskusi terjadi pada saat siswa saling mempertanyakan jawaban yang dikerjakan teman sekelompoknya. Di sinilah TAI dirancang untuk menyelesikan masalahmasalah teoritis dan praktis dari sistem pembelajaran.

Hasil penelitian ini sejalan dengan penelitian yang dilakukan oleh Erwanda (2017) yang menyatkan bahwa model pembelajaran kooperatif tipe Team Accelerated Instruction (TAI) ini mengacu pada pembelajaran yang sering menggunakan model pembelajaran konvesional, pembelajaran yang memuat keaktifan guru dalam penyampaian pembelajaran yang menjadikan siswa pasif. Untuk itu digunakan model ini untuk mengatasi siswa yang pasif menjadi aktif, model TAI ini juga dapat mengatasi kesulitan belajar siswa secara individual.

Penelitian yang telah dilakukan oleh peneliti secara optimal sangat disadari masih adanya kesalahan dan kekurangan. Hal itu dikarenakn keterbatasan penulis diantaranya: (1) Keterbatasan waktu, penelitian yang dilakukan oleh peneliti terpancang oleh waktu, karena waktu yang digunakan sangat terbatas. Maka penelitian ini dilakukan hanya sesuai keperluan yang berhubungan dengan penelitian saja. (2) Keterbatasan kemampuan dan analisis, suatu penelitian tidak akan lepas dari pengetahuan dengan demikian penelitian ini mempunyai keterbatasan kemampuan, khususnya pengetahuan dalam pembuatan karya ilmiah. Tetpi peneliti telah berusaha semaksimal mungkin untuk menjalankan penelitian sesuai dengan kemampuan peneliti dan dari arahan dosen pembimbing. (3) Keterbatasan dalam pelaksanaan proses belajar mengajar, pada saat proses belajar mengajar juga belum sempurna, masih ada siswa yang gaduh dan masih sangat memerlukan bimbingan dari guru.

\section{SIMPULAN}

Berdasarkan hasil analisis data dalam penelitian ini dapat disimpulkan bahwa: (1) Berdasarkan hasil pengujian Regresi Linear Sederhana dapat diketahui bahwa nilai signifikan (Sig.) sebesar 0,000 lebih kecil dari probabilitas 0,05 , sehingga dapat disimpulkan bahwa $\mathrm{H}_{0}$ diterima, yang berarti bahwa terdapat pengaruh model pembelajaran kooperatif tipe Team Accelerated Instruction (TAI) terhadap kemampuan pemecahan masalah matematika materi pola bilangan, (2) Berdasarkan hasil pengujian koefisien determinasi dapat diketahui bahwa nilai $R$ Square adalah 0,415 . Sehingga 


\section{Jurnal Hipotenusa, 1 (1), Desember 2019}

Aniyatul Jaziroh

besar pengaruh model pembelajaran kooperatif tipe Team Accelerated Instruction (TAI) terhadap kemampuan pemecahan masalah sebesar 41,5\%, dan selebihnya 58,5\% dipengaruhi oleh faktor lain.

Beradasarkan penelitian yang sudah dilakukan, ada beberapa saran yang ditujukan kepada pihak tertentu sebagai bahan pertimbangan untuk penelitian yang akan datang: (1) Monitoring guru terhadap kegiatan belajar mengajar karena model pembelajaran kooperatif tipe Team Accelerated Instruction (TAI) akan maksimal jika kerjasama dalam suatu kelompok dapat berjalan dengan efektif dan efisien. Sehingga tidak hanya siswa yang pandai yang bekerja, tetapi semua siswa dalam kelompok tersebut dituntut untuk aktif. Sehingga siswa yang kurang, akhirnya dapat menyesuaikan dengan siswa yang mempunyai kemampuan lebih, (2) Bagi para siswa, diharapkan lebih aktif dalam proses belajar mengajar dan selalu meningkatkan belajarnya sehingga dapat mencapai hasil yang maksimal, (3) Bagi peneliti yang akan melakukan penelitian yang serupa dengan menggunakan model pembelajaran kooperatif tipe Team Accelerated Instruction (TAI), hendaknya menambahkan faktor lain sehingga penelitian selanjutnya terlihat pengaruhnya terhadap kemampuan siswa.

\section{DAFTAR PUSTAKA}

Erwanda, Lidza Yuniar. 2017. Penerapan Model Pembelajaran Kooperatif Tipe Team Accelerated Instruction (TAI) Untuk Meningkatkan Motivasi Belajar Dan Hasil Belajar Pada Kompetensi Dasar Menyusun Workhsheet Siswa Kelas X AK 1 SMK YPKK 1 Sleman Tahun Ajaran
2016/2017. Skripsi. Tidak Diterbitkan. Fakultas Ekonomi. Universitas Negeri Yogyakarta: Yogyakarta.

Himawan, Khirzul Falah. 2016. Pengaruh Penerapan Model Kooperatife Tipe Team Accelerated Instruction (TAI) Terhadap Hasil Belajar Peserta Didik Pada Mapel IPA Kelas VII MTs Nurussalam Tersono Kab. Batang Tahun Ajaran 2015/2016. Skripsi. Tidak diterbitkan. Fakultas Sains dan Teknologi. Universitas Islamn Negeri Walisongo: Semarang.

Mulyasa, E. 2008. Menjadi Guru Profesional \& Menciptakan Pembelajaran Kreatif dan Menyenangkan. Bandung: Remaja Rosdakarya.

Purwanto, Erwan Agus dan Dyah Ratih Sulistyastuti. 2017. Metode Penelitian Kuantitatif Untuk Administrasi Publik dan Masalah-masalah Sosial. Yogyakarta: Gava Media.

Putro, Yudha Adi dan Mustapha Kamal. 2013. Analisis Pengaruh Brand Reputation, Brand Competence, dan Brand Liking Terhadap Trust In Brand Pada Konsumen Windows Phone Nokia di Surabaya. Jurnal Studi Manajemen \&organisasi. Vol 10 No 2.

Sugiyono. 2017. Metode Penelitian Pendidikan Pendekatan Kuantitatif, Kualitatif, dan $R \& D$. Bandung: Alfabeta.

Trianto. 2011. Model-Model Pembelajaran Inovatif Berorientasi Konstruktivistik. Jakarta: Prestasi Pustaka. 